\title{
AS DIFERENTES POSSIBILIDADES DE APRENDIZAGENS QUE OS ESPAÇOS NATURAIS PROPORCIONAM PARA AS CRIANÇAS NA EDUCAÇÃO INFANTIL
}

\section{THE DIFFERENT POSSIBILITIES OF LEARNING THAT NATURAL SPACES PROVIDE FOR CHILDREN IN CHILD EDUCATION}

\author{
Ellen Matos Frigo Melo ${ }^{1}$ \\ Andréa Rabelo Marcelino ${ }^{2}$
}

\begin{abstract}
RESUMO: Este artigo aborda uma pesquisa sobre as diferentes possibilidades de aprendizagens que os espaços naturais proporcionam para as crianças na educação infantil. Teve como objetivo de estudo analisar os espaços naturais que possibilitam o bem-estar das crianças em uma turma na Educação Infantil. As referências utilizadas para compreender o processo de aprendizagem da criança na educação infantil foram: Dourado (2012), Brasil (2018), Kramer (2007) e Vigotski (1998). Através da análise em documentos oficiais buscouse entender a função da educação infantil e, para compreender o conceito de espaço, bem como, o papel do educador foram pesquisadas as referências: Santos (2008), Almeida e Passini (1989), Horn (2004), Horn (2017), Tiriba (2018) e Rinaldi (2012). A pesquisa de campo foi realizada por meio de questionário aberto com dois educadores de três escolas da rede particular de Criciúma - SC. A pesquisa evidenciou que os educadores estão cientes de que a realização de suas propostas no ambiente externo contribui para melhorar o processo de ensino e aprendizagem na educação infantil.
\end{abstract}

PALAVRAS CHAVE: Aprendizagem. Educação Infantil. Espaço Externo.

ABSTRACT: This article discusses the different learning possibilities that natural spaces provide for children in early childhood education. The objective of this study was to analyze the natural spaces that enable the well-being of children in a class in kindergarten. The references used to understand the learning process of children in early childhood education were: Dourado (2012), Brazil (2018), Kramer (2007) and Vigotski (1998). Through the analysis in official documents we sought to understand the function of early childhood education and, to understand the concept of space, as well as the role of the educator were researched the references: Santos (2008), Almeida and Passini (1989), Horn (2004), Horn (2018), Tiriba (2018) and Rinaldi (2012). The field research was conducted through an open questionnaire with two educators from three schools of the private network of Criciúma - SC. The research showed that educators are aware that the realization of their proposals in the external

${ }^{1}$ Graduada em Pedagogia da UNESC. Email: ellen_frigo@yahoo.com.br.

${ }^{2}$ Graduada em Geografia e Pedagogia. Mestre em Educação, UNESC. Email: armarcelino@unesc.net.

Saberes Pedagógicos, Criciúma, v. 4, n², maio/agosto 2020.- Curso de Pedagogia- UNESC 
environment contributes to improve the teaching and learning process in early childhood education.

KEYWORDS: Learning. Child education. Outer Space.

\section{INTRODUÇÃO}

Desde que iniciei meu trabalho na educação infantil e no Curso de Pedagogia, pude observar como as crianças necessitam brincar e explorar os espaços externos para promover a interação social, a aprendizagem e o desenvolvimento desde os primeiros anos de vida.

Diante disso, surgiu o interesse em buscar outros meios que pudesse pesquisar como os espaços externos possibilitam o processo de aprendizagem das crianças em idade pré-escolar.

De acordo com Horn (2017), as crianças, na sua maioria, vivem em apartamentos e as que vivem em casas, muitas vezes, não possuem um espaço para brincar ao ar livre. Os centros urbanos estão cada vez mais verticalizados, com poucas praças para frequentar e explorar os ambientes externos. A violência inibe os pais de deixarem seus filhos brincarem na rua. As escolas, também limitam estes espaços, não permitindo as crianças explorarem seus ambientes, construindo calçadas para evitar a sujeira e preferem estar em sala de aula, pois acreditam que a aprendizagem só é possível com atividades em papel e lápis.

Como trabalho em uma escola que proporciona um espaço considerado privilegiado, com pomar, campo, jardim sensorial, parque com muitas árvores e até mesmo um chuveirão, possibilitando ter o contato das crianças com a natureza e perceber como o brincar com a terra, com a água, escalar morro, pendurar-se em árvores, faz dos espaços externos a criação de suas próprias brincadeiras.

Com isso, o presente artigo traz um olhar por meio de questionamentos realizados com professoras de pré-escolas da educação infantil na cidade de Criciúma - SC. Questionamentos estes, que possibilitam analisar como estas professoras proporcionam suas metodologias nos ambientes externos. Sendo assim, apresenta-se como tema: “As diferentes possibilidades de aprendizagens que os espaços naturais proporcionam para as crianças na Educação Infantil". Em virtude disso, o problema da pesquisa destaca-se sobre: Como os espaços naturais possibilitam o bem-estar das crianças na Educação Infantil?

Saberes Pedagógicos, Criciúma, v. 4, n², maio/agosto 2020.- Curso de Pedagogia- UNESC 
A pesquisa teve como objetivo geral, analisar os espaços naturais que possibilitam o bem-estar das crianças em uma turma na Educação Infantil. Desta forma destacam-se os objetivos específicos: Verificar como acontece o processo de ensino e aprendizagem na educação infantil; Identificar a função da educação infantil (4 a 5 anos) segundo os documentos oficiais; Conhecer de que forma os espaços externos contribuem para o bem-estar das crianças na Educação Infantil e, Identificar o papel do educador na organização e utilização dos espaços da Educação Infantil.

O referencial teórico desta pesquisa está dividido em três capítulos. O primeiro refere-se ao processo de aprendizagem da criança na educação infantil, após será abordado a função da educação infantil de acordo com a legislação e o terceiro capítulo traz o espaço geográfico e o papel do educador na educação infantil.

Os principais autores pesquisados para compreender como os espaços naturais influenciam na aprendizagem foram: Kramer (2007) e Vigotski (1998). Para entender se a função da educação infantil está de acordo com a legislação, buscou-se em Brasil (2013), Brasil (2017) e Brasil (2018). A fim de conceituar espaço geográfico e trazer o papel do educador utilizou-se os seguintes autores: Santos (2008), Almeida e Passini (1989), Tiriba (2018), Horn (2004), Horn (2017) e Rinaldi (2012). Esses autores embasaram esta pesquisa.

Como metodologia utilizou-se a pesquisa básica, com característica descritiva, e a análise de dados coletada através de questionário com dois educadores de três escolas de educação infantil da rede particular de Criciúma - SC. Assim sendo, este artigo está organizado com uma introdução, três capítulos, uma metodologia e a análise de dados correlacionando com o referencial teórico. Por fim, as considerações finais e as referências bibliográficas que deram suporte a este artigo.

\section{O PROCESSO DE APRENDIZAGEM DA CRIANÇA NA EDUCAÇÃO INFANTIL}

Na década de 1970, a educação infantil no Brasil teve sua expansão quando as mulheres começaram a ingressar no mercado de trabalho, havendo assim, a necessidade de um lugar para seus filhos ficarem tendo seu papel apenas no cuidar, não havendo uma preocupação pedagógica de ensino. "As creches preenchiam esta necessidade para a classe Saberes Pedagógicos, Criciúma, v. 4, n², maio/agosto 2020.- Curso de Pedagogia- UNESC 
trabalhadora. Firmando-se assim, o cuidar, a atividade principal dessas instituições" (DOURADO, 2012).

Foi então, no ano de 1988, quando a Constituição Federal torna dever do Estado o atendimento em creches e pré-escolas para crianças de zero a seis anos. A partir disso, a educação infantil começou a ser reconhecida, não só como um processo de cuidar, mas também com a necessidade em educar. Segundo a Base Nacional Comum Curricular,

\begin{abstract}
Nas últimas décadas, vem se consolidando, na Educação Infantil, a concepção que vincula educar e cuidar, entendendo o cuidado como algo indissociável do processo educativo. Nesse contexto, as creches e pré-escolas, ao acolher as vivências e os conhecimentos construídos pelas crianças no ambiente da família e no contexto de sua comunidade, e articulá-los em suas propostas pedagógicas, têm o objetivo de ampliar o universo de experiências, conhecimentos e habilidades dessas crianças, diversificando e consolidando novas aprendizagens, atuando de maneira complementar à educação familiar - especialmente quando se trata da educação dos bebês e das crianças bem pequenas, que envolve aprendizagens muito próximas aos dois contextos (familiar e escolar), como a socialização, a autonomia e a comunicação (BRASIL, 2018, p.36).
\end{abstract}

A primeira etapa de vida de um recém-nascido acontece quando chega ao mundo e descobre um universo misterioso cheio de sons, cores e significados que são adquiridos no meio em que vivem. Para Vigotski (1994), citado por Kramer, “esse meio no qual a criança vive e atua apresenta-se como um lugar carregado de significados, carregado de ideologia, história e cultura, onde não cabe pensar num ser abstrato, neutralizado" (KRAMER, 2007, p.258).

O bebê passa a sentir o mundo que está em sua volta e, através de estímulos, inicia seu processo de aprendizagem, observando os adultos e explorando seu ambiente. "O aprendizado é mais do que aquisição de capacidade para pensar; é a aquisição de muitas capacidades especializadas para pensar sobre várias coisas” (VIGOTSKI, 1998, p.108).

Nesse processo de aprendizagem, as crianças precisam estar em contato com o lúdico, no qual as brincadeiras são de fundamental importância para o seu desenvolvimento, pois permitem que vivenciem experiências do seu cotidiano criando condições para desenvolverem suas relações com o ambiente em que estão inseridas. "A interação durante o brincar caracteriza o cotidiano da infância, trazendo consigo muitas aprendizagens e potenciais para o desenvolvimento integral das crianças" (BRASIL, 2018, p.37). 
As crianças aprendem de diferentes maneiras porque são diferentes. Aprendem brincando, explorando, observando e aprendem umas com as outras nas trocas e na beleza do cotidiano. O meio em que estão inseridas possui influência neste processo de ensino e aprendizagem.

O jogo com regras é uma das estratégias que facilitará nesta aprendizagem, contribuindo assim, com a compreensão e interpretação das próprias regras: racionais, lógica, tempo estimado para a realização do mesmo, convívio entre as crianças, entre outros.

[...] a principal contribuição da brincadeira no desenvolvimento da criança é a criação de uma nova relação entre o campo do significado e o campo da percepção visual. Assim sendo, quando a criança brinca, ela normalmente mostra no jogo um comportamento mais sofisticado do que aquele que ela, normalmente apresenta na vida diária. No jogo, a criança demonstra a consciência que possui das regras e dos valores de convívio com a realidade. Porém, mais do que se conformar e reproduzir essas regras, a criança reelabora-as criativamente, combinando-as entre si e edificando com ela novas possibilidades de interpretação e representação do real (KRAMER, 2007, p.53).

Vygotski (1998), citado por Kramer (2007, p.53) "chamou de zona de desenvolvimento proximal todo comportamento que a criança apresenta no jogo, mas que raramente transparece na vida diária”. No entanto, Piaget citado por Kramer (2007, p. 54) entende que:

\footnotetext{
O jogo é simplesmente a predominância da assimilação sobre a acomodação, posto que, ao invés da criança submeter a realidade, é a realidade que constrange a criança impondo-se a ela. [...] Portanto, jogo, na perspectiva piagetiana, é "prática" e "repetição"; sua distinção da atividade séria é uma questão apenas de grau (BuckMorss, 1987). (KRAMER, 2007, p.54).
}

Percebe-se que as crianças gostam de brincar várias vezes das mesmas coisas e isso oportuniza a ressignificarem o que já vivenciaram. É por meio das brincadeiras que compreendem o mundo ao seu redor e manifestam seus sentimentos. O brincar emancipa a criança. Traz a ela a oportunidade de ser o que quiser e viajar por onde desejar.

O brincar define muitas aprendizagens para o desenvolvimento das crianças, pois é através da brincadeira que a criança entra no mundo da ludicidade, despertando a criatividade e imaginação para potencializar o seu próprio conhecimento. De acordo com Brasil,

Saberes Pedagógicos, Criciúma, v. 4, n², maio/agosto 2020.- Curso de Pedagogia- UNESC 
[...] Seis direitos de aprendizagem e desenvolvimento asseguram, na Educação Infantil, as condições para que as crianças aprendam em situações nas quais possam desempenhar um papel ativo em ambientes que as convidem a vivenciar desafios e a sentirem-se provocadas a resolvê-los, nas quais possam construir significados sobre si, os outros e o mundo social e natural. [...] diretos de aprendizagem e desenvolvimento: conviver, brincar, participar, explorar, expressar, conhecer-se (BRASIL 2018, p.37- 38).

Desse modo, faz-se necessário pensar em educação infantil como um importante processo de desenvolvimento e aprendizagem em todos os momentos que estão inseridos no cotidiano escolar, desde os primeiros anos de vida.

Sendo assim, a aprendizagem que a criança adquire ao ingressar na educação infantil reflete uma importante base para estimular o seu desenvolvimento, despertar sua curiosidade e criar vínculos com o ambiente escolar em que está inserida.

\section{A FUNÇÃO DA EDUCAÇÃO INFANTIL DE ACORDO COM A LEGISLAÇÃO}

A crescente mudança na estrutura familiar, juntamente com a modernidade e a industrialização, fez com que as escolas de educação infantil tivessem um crescimento acentuado nos últimos anos, fazendo com que as famílias optassem por deixar seus filhos em instituições de ensino para que pudessem permanecer no mercado de trabalho.

A partir disso, a lei no 9.394/1996 do artigo 29 (Seção II) da Lei de Diretrizes e Bases aborda que, “A educação infantil, primeira etapa da educação básica, tem como finalidade o desenvolvimento integral da criança de até 5 (cinco) anos, em seus aspectos físico, psicológico, intelectual e social, complementando a ação da família e da comunidade" (BRASIL, 2018, p. 22).

Sendo esta a primeira etapa, a educação infantil insere a criança em um grupo social que se difere do seu ambiente familiar, estabelecendo vínculos com outras crianças e educadores, construindo um processo de ensino e aprendizagem por meio de atividades que desenvolvam a sua formação.

Seu papel não é alfabetizar, mesmo que muitas vezes se encontram escolas e famílias que não permitem a construção da criança como seu processo de desenvolvimento 
integral, focando assim, apenas na alfabetização, mas desenvolver interesses que possam contribuir para que este processo se torne espontâneo. Sendo assim, as Diretrizes Curriculares Nacionais para a Educação Infantil afirmam que,

[...] "têm se mostrado prioritárias as discussões sobre como orientar o trabalho junto às crianças de até três anos em creches e como garantir práticas junto às crianças de quatro e cinco anos que se articulem, mas não antecipem processos do Ensino Fundamental" (BRASIL, 2013, p. 82).

E ainda, segundo a Base Nacional Comum Curricular,

A expressão educação "pré-escolar", utilizada no Brasil até a década de 1980, expressava o entendimento de que a Educação Infantil era uma etapa anterior, independente e preparatória para a escolarização, que só teria seu começo no Ensino Fundamental. Situava-se, portanto, fora da educação formal (BRASIL, 2018, p.35).

Dessa maneira, a educação infantil traz uma formação importante no desenvolvimento das crianças, pois este contato que ela exerce em um meio fora do seu contexto familiar, estimula a sua aprendizagem, adquirindo conhecimentos que serão importantes durante a sua vida. De acordo com a Base Nacional Comum Curricular,

\begin{abstract}
Ainda, é preciso acompanhar tanto essas práticas quanto as aprendizagens das crianças, realizando a observação da trajetória de cada criança e de todo o grupo suas conquistas, avanços, possibilidades e aprendizagens. Por meio de diversos registros, feitos em diferentes momentos tanto pelos professores quanto pelas crianças (como relatórios, portfólios, fotografias, desenhos e textos), é possível evidenciar a progressão ocorrida durante o período observado, sem intenção de seleção, promoção ou classificação de crianças em "aptas" e "não aptas", "prontas" ou "não prontas", "maduras" ou "imaturas". Trata-se de reunir elementos para reorganizar tempos, espaços e situações que garantam os direitos de aprendizagem de todas as crianças (BRASIL, 2018, p. 39).
\end{abstract}

Os processos que acontecem durante o período da educação infantil, fazem com que as crianças desenvolvam suas habilidades e interesses, explorando o mundo a sua volta com propostas que permitem sua aprendizagem, seus saberes e relações interpessoais, desenvolvendo suas capacidades, conhecendo-se, expressando suas conquistas e sentimentos nas diferentes linguagens que utiliza para sua comunicação. 
Sendo assim, conseguimos observar a importância do espaço preparado pelo educador para que desenvolva as potencialidades das crianças de maneira significativa. Sua correta utilização e a intervenção desses educadores têm papel fundamental nesse processo que é utilizado para aprimorar as habilidades das crianças, explorando os diferentes espaços da escola.

A ação de planejar, portanto, não se reduz ao simples preenchimento de formulários para controle administrativo; é, antes, a atividade consciente de previsão das ações docentes, fundamentadas em opções político-pedagógicas, e tendo como referência permanente as situações didáticas concretas (isto é, a problemática social econômica, política e cultural que envolve a escola, os professores, os alunos, os pais, a comunidade, que interagem no processo de ensino (LIBÂNEO, 1994, p.222).

Logo, é importante que o educador tenha organizado seu planejamento de acordo com a área do conhecimento que vai auxiliar nas atividades para essa fase de escolaridade.

No capítulo seguinte, trataremos da importância do espaço geográfico e o papel do educador na educação infantil.

\section{O ESPAÇO GEOGRÁFICO E O PAPEL DO EDUCADOR NA EDUCAÇÃo INFANTIL}

O espaço é o lugar que ocupamos no meio em que estamos inseridos, sendo este natural ou cultural. Conforme cita Milton Santos,

\footnotetext{
O espaço deve ser considerado como um conjunto indissociável, de que participam, de um lado, certo arranjo de objetos geográficos, objetos naturais e objetos sociais, e, de outro, a vida que os preenche e os anima, ou seja, a sociedade em movimento. [...] O espaço, por conseguinte, é isto: um conjunto de formas contendo cada qual frações da sociedade em movimento. As formas, pois, têm um papel na realização social (SANTOS, 2008, p. 30-31).
}

Na educação infantil, a noção de espaço passa por etapas fundamentais que irão auxiliar na construção de conhecimentos da criança, conhecimento este segundo (ALMEIDA; PASSINI, 1989, p.26) trata como espaço "do vivido ao percebido e deste ao concebido". Por 
isso a importância em que a criança vivencie cada espaço no seu tempo e perceba a construção que este se dá ao longo de sua vida.

Conforme esta noção de espaço se dá em suas observações, a criança toma consciência do seu próprio corpo e passa a identificar suas próprias dimensões. "A análise de espaço, deve ser iniciada com a criança primeiramente com o corpo, em seguida apenas com os olhos e finalmente com a mente" (ALMEIDA; PASSINI, 1989, p.30).

Ao longo dos tempos, foi-se percebendo na educação infantil, a importância dos espaços preparados para acolher as crianças, desenvolver as suas competências e estimular o seu desenvolvimento. “A arquitetura dos espaços escolares reflete muito a concepção de conhecimento, de aprendizagem e de sociedade que embasa o projeto político pedagógico de cada instituição” (TIRIBA, 2018, p.29). Quando se fala de espaço, pensamos em seu meio físico e o que ele pode nos proporcionar dentro da escola. Como as crianças usam este ambiente para suas brincadeiras, jogos, relações interpessoais, autonomia para desenvolver e possibilitar suas aprendizagens e seu convívio escolar. De acordo com Horn:

\footnotetext{
É no espaço físico que a criança consegue estabelecer relações entre o mundo e as pessoas, transformando-o em um pano de fundo no qual se inserem emoções [...] nessa dimensão o espaço é entendido como algo conjugado ao ambiente e vice-versa. Todavia é importante esclarecer que essa relação não se constitui de forma linear. Assim sendo, em um mesmo espaço podemos ter ambientes diferentes, pois a semelhança entre eles não significa que sejam iguais. Eles se definem com a relação que as pessoas constroem entre elas e o espaço organizado" (HORN, 2004, p.28).
}

As crianças necessitam estar inseridas no espaço desde suas primeiras explorações para que possam ter contato com este universo, possibilitando sua socialização com as pessoas que fazem parte do seu cotidiano. "Desde os primeiros meses de vida do ser humano delineiamse as impressões e percepções referentes ao domínio espacial, as quais desenvolvem-se através de sua interação com o meio" (ALMEIDA; PASSINI, 1989, p.11).

Através da exploração dos espaços que encontramos na escola passamos a conhecer os ambientes que fazem parte desse território. "É preciso levar os espaços escolares para além das salas de aula e potencializar um uso pelos estudantes que transcenda as tradicionais funcionalidades da instituição escolar" (TIRIBA, 2018, p.30). 
Com isso, nosso olhar se volta para o ambiente externo, possibilitando um contato que oferece as crianças uma observação investigativa com a natureza, criando assim, experiências que serão importantes para o seu desenvolvimento, pois o brincar ao ar livre, em diferentes situações, provoca uma sensação de liberdade e conectividade com o espaço natural. Caobelli (2013), citado por Horn (2017, p.87), salienta alguns dos efeitos positivos que os espaços externos proporcionam para o processo de ensino e aprendizagem na educação infantil, tais como:

Desenvolvimento do poder e da criatividade, promoção do uso da linguagem e das
habilidades cooperativas, alívio do estresse e possibilidade de lidar com as
adversidades, auxílio no tratamento a crianças com déficit de atenção, melhor
desempenho da coordenação motora, e desenvolvimento da imaginação e despertar
de um sentimento de admiração pelo mundo (HORN, 2017, p.87).

Desse modo, é necessário pensar nesse espaço disponibilizado e quais relações começam a ser estabelecidas podendo ser entre adultos e crianças, criança e criança e criança e o meio, promovendo assim um crescimento intrapessoal e interpessoal.

$\mathrm{O}$ olhar atento que o educador proporciona para o ambiente externo torna seu cotidiano importante em buscar novas perspectivas para atender as necessidades que cada criança possui ao explorar suas experiências.

A importância da pesquisa constante do educador se faz necessária durante seu planejamento e na própria atuação frente às crianças, trazendo assim, situações para o desenvolvimento da Educação Infantil. Para Freire (1996), “o professor precisa ter disciplina diária para estudar e ampliar seu saber, pois é a partir desse hábito que ele se torna um pesquisador de novas práticas educativas". Por isso, os cursos de formação continuada são de extrema importância para a prática pedagógica dos educadores.

$\mathrm{O}$ planejamento requer um alinhamento do que será proposto durante o ano. Planejar suas ações, conhecer as necessidades e a realidade do meio que será desenvolvido sua metodologia, traçar objetivos a serem alcançados, traz segurança na organização tanto do tempo, como do espaço e materiais que serão utilizados e desenvolvidos durante as propostas realizadas. Para a efetivação do planejamento, o professor organiza de acordo com o objetivo a ser alcançado, podendo prever para um dia, uma semana, mensal ou até mesmo anual. 
O planejamento se concretiza em planos e projetos, tanto da escola e do currículo quanto do ensino. Um plano ou um projeto é um esboço, um esquema que representa uma ideia, um objetivo, uma meta, uma sequência de ações que irão orientar a prática. A ação de planejar subordina-se à natureza da atividade realizada. No planejamento escolar, o que se planeja são as atividades de ensino e de aprendizagem, fortemente determinadas por uma intencionalidade educativa envolvendo objetivos, valores, atitudes, conteúdos, modo de agir dos educadores que atuam na escola. Em razão disso, o planejamento nunca é apenas individual, é uma prática de elaboração conjunta dos planos e sua discussão pública (LIBÂNEO, 2015, p.125).

O modo como o educador conduzirá seu trabalho dependerá da mediação que ele terá diante da criança. A maneira que ele escuta, sente, cria oportunidades para o seu desenvolvimento e na busca constante por aperfeiçoamento de sua prática na sala de aula. Segundo Rinaldi:

\footnotetext{
O papel do professor é o de protagonista e é inerentemente respeitado. Esse respeito se deve à competência e à inteligência com que o professor é chamado a desempenhar o seu papel. A definição de identidade profissional do professor, então, não é vista em termos abstratos, mas em contextos, em relação aos colegas, aos pais e, acima de tudo, às crianças, mas também em relação a sua própria identidade e à sua formação pessoal e educacional, além da sua experiência (RINALDI, 2012, p.106).
}

Por isso, o educador deve ter uma visão reflexiva, crítica perante os vários desafios que a profissão proporciona diante de sua prática e do processo de ensino e aprendizagem que as crianças encontram neste primeiro estágio da educação.

O papel que este profissional desempenha será o diferencial no processo de formação da criança, sendo importante o método que este desempenha em suas atividades, levando a criança para explorar ambientes que vão além das salas de aula.

Assim como o desemparedamento das crianças é essencial, o desemparedamento dos educadores em formação é uma necessidade, uma consequência. As atividades de sensibilização e de experimentação podem e devem ganhar espaço crescente nos processos de formação. Afinal, se o lugar de aprender e viver é o lado de fora, isso também se aplica às formações de professores, que podem ser realizadas num piquenique, nos espaços da escola ou em parques da cidade. (TIRIBA, 2018, p. 47).

Ter em mente que os ambientes externos da escola, muitas vezes, são os únicos momentos que proporcionam a esta criança o brincar ao ar livre, faz disso um encontro com a natureza, desfrutando de recursos naturais diversos e explorando a imaginação nas diversas brincadeiras que surgem. Professores devem estar abertos a estas propostas inserindo as Saberes Pedagógicos, Criciúma, v. 4, n², maio/agosto 2020.- Curso de Pedagogia- UNESC 
experiências naturais no seu cotidiano, no qual “[...] o brincar e o aprender na natureza são essenciais e possíveis - para empreender verdadeiras mudanças no sentido de desemparedar as crianças" (TIRIBA, 2018, p.51).

Somente por meio de um novo olhar sobre esses ambientes tornarão as aprendizagens mais potentes e significativas e, ao mesmo tempo, prazerosa para os educadores.

\section{METODOLOGIA, APRESENTAÇÃO E ANÁLISE DE DADOS}

A pesquisa nos proporciona a buscar um conhecimento para determinado assunto que nos desperta a curiosidade para aprender mais. De acordo com Gil (2002, p.17) “a pesquisa desenvolve-se ao longo de um processo que envolve inúmeras fases, desde a adequada formulação do problema até a satisfatória apresentação dos resultados".

A pesquisa a ser realizada neste trabalho pode ser classificada quanto a sua natureza, uma pesquisa básica, para que se possa ter um conhecimento de como os espaços naturais possibilitam o bem-estar das crianças em uma turma de Educação Infantil. De acordo com o autor Pinheiro (2010, p.19), “A pesquisa básica tem como objetivo gerar conhecimentos para o avanço da ciência sem aplicação prática prevista”.

Quanto ao objetivo da pesquisa é de característica descritiva, pois visa encontrar elementos essenciais que permitam um contato com espaços naturais possibilitando o bem-estar das crianças. Segundo Gil (2002, p.42), “As pesquisas descritivas têm como objetivo primordial a descrição das características de determinada população ou fenômeno ou, então, o estabelecimento de relações entre variáveis". Como instrumento utilizado para realização desta pesquisa, um questionário com perguntas abertas foi aplicado de modo que o entrevistado respondesse de maneira espontânea, usando sua opinião de acordo com suas vivências e práticas diárias.

Buscou-se por meio da abordagem qualitativa, entender de que forma os entrevistados realizam suas ações para alcançar os objetivos propostos na problemática estudada. "A pesquisa qualitativa caracteriza-se pela tentativa de uma compreensão detalhada dos significados e características situacionais apresentadas pelos entrevistados [...]" (PINHEIRO, 2010, p.20).

Saberes Pedagógicos, Criciúma, v. 4, n², maio/agosto 2020.- Curso de Pedagogia- UNESC 
Para desenvolver esta pesquisa, foram entrevistados dois professores de três escolas de educação infantil da rede particular do município de Criciúma - SC. A entrevista aconteceu através de um questionário aplicado com perguntas abertas onde cada entrevistado respondeu de acordo com sua vivência e prática em turmas de pré-escolar.

As professoras que participaram da pesquisa terão seus nomes em sigilo. E estão aqui representadas por nomes fictícios para preservar a identidade delas, utilizando sinônimos com elementos que encontramos nos espaços naturais do ambiente escolar apresentadas no quadro a seguir.

Quadro 01- Professores que participaram da pesquisa.

\begin{tabular}{|l|l|l|}
\hline Professores & Formação & Tempo de experiência \\
\hline $1-$ Rocha & Graduada em Pedagogia. Pós-graduada em Gestão Escolar & 13 anos \\
\hline $2-$ Terra & Graduada em Pedagogia. Pós-graduada em Psicopedagogia & 4 anos \\
\hline $3-$ Água & $\begin{array}{l}\text { Graduada em Pedagogia. Pós-graduada em Neuropsicopedagogia } \\
\text { Institucional e Educação, Especial Inclusiva }\end{array}$ & 2 anos \\
\hline $4-$ Flor & $\begin{array}{l}\text { Magistério, Graduada em Pedagogia e Pós-graduada em } \\
\text { Psicopedagogia }\end{array}$ & 20 anos \\
\hline $5-$ Folha & $\begin{array}{l}\text { Graduada em Pedagogia, Pós-graduada em Neuropsicopedagogia } \\
\text { Institucional e Educação Especial Inclusiva }\end{array}$ & 17 anos \\
\hline $6-$ Semente & $\begin{array}{l}\text { Magistério, Licenciatura Plena em Matemática } \\
\text { Pós-Graduada em Educação Matemática }\end{array}$ \\
\hline
\end{tabular}

Fonte: MELO, 2019.

No quadro 01 apresentou-se o número de professores que participaram da pesquisa sobre "As diferentes possibilidades de aprendizagens que os espaços naturais proporcionam as crianças na educação infantil", sendo que, o primeiro questionamento se refere a formação de cada uma das pesquisadas, bem como os anos de experiência. Para preservar o sujeito da pesquisa, optou-se pelo uso de sinônimos que está relacionado aos elementos do espaço natural. Neste sentido para a professora 1 vamos utilizar Rocha, a professora 2 - Terra, 3 - Água, 4 Flor, 5 - Folha e para a professora 6 - Semente.

Percebe-se no quadro que, das professoras entrevistadas, somente uma não possui graduação em Pedagogia, tendo licenciatura em Matemática, porém, cursou magistério. Existem professoras com o mesmo curso de Pós-graduação, sendo duas em Psicopedagogia e outras duas em Neuropsicopedagogia Institucional e Educação Especial Inclusiva. As 
professoras entrevistadas possuem um bom período de experiência, o que demonstra bom desempenho em suas atividades descritas.

Por fim, para apresentar a coleta de dados definiram-se categorias de análise, sendo eles: A importância do planejamento e do uso de diferentes metodologias para a efetivação da aprendizagem e, os espaços de aprendizagem da educação infantil.

$\mathrm{Na}$ sequência, será apresentada a análise dos questionamentos realizados na pesquisa.

\subsection{A importância do planejamento e do uso de diferentes metodologias para a efetivação da aprendizagem}

A análise desta pesquisa terá como objetivo apresentar o modo como as professoras participantes desenvolvem suas propostas e metodologias atuando nas diferentes possibilidades que os espaços naturais proporcionam para as crianças.

Quando perguntadas sobre a organização de seus planejamentos, observou-se que as professoras realizam de forma semanal ou mensal, podendo ser alterados conforme sua realização. As metodologias utilizadas para desenvolverem suas atividades e garantir o processo de ensino e aprendizagem acontecem de forma lúdica, partindo do interesse, escuta e observação das crianças para que esta aprendizagem se torna um momento de interesse em buscar o novo. A professora Terra descreve que: "Utilizo diferentes materiais, principalmente não estruturados e elementos da natureza. O espaço da sala se torna um terceiro educador, pois a mesma vai proporcionando descobertas ao longo do dia sem ser apenas no momento da proposta/atividade direcionada. Também usamos recursos tecnológicos e o espaço externo com frequência".

Sabendo-se que as crianças aprendem de diferentes formas e é através das brincadeiras e jogos que essa aprendizagem se torna mais intensa, inserindo esta criança no mundo da ludicidade, despertando seu interesse e tornando este processo de ensino e aprendizagem um momento importante no seu desenvolvimento. Assim como a professora Folha destaca em sua resposta: "Utilizo muitas brincadeiras para que os alunos tenham uma aprendizagem divertida e melhor compreendida através do lúdico. Procuro sempre instigá-los

Saberes Pedagógicos, Criciúma, v. 4, n², maio/agosto 2020.- Curso de Pedagogia- UNESC 
a descobrir soluções para suas dúvidas e problemáticas. Sempre que surge dúvidas ou polêmicas de algum assunto, trabalho esse “assunto" nos projetos”. Segundo Rinaldi (2012):

A tarefa do educador é criar um contexto em que a curiosidade, as teorias e a pesquisa das crianças sejam legitimadas e ouvidas, um contexto em que as crianças se sintam confortáveis e confiantes, motivadas e respeitadas em seus processos e percursos cognitivos e existenciais (RINALDI, 2012, p.228).

Com análise nas respostas, pode-se notar que a escuta está inserida nessa investigação, assim como as brincadeiras fazem parte para que o processo de ensino e aprendizagem se torne um momento de estimular seu desenvolvimento.

De acordo com a Lei de Diretrizes e Bases da Educação Nacional, percebeu-se que as educadoras desenvolvem este processo respeitando a individualidade de cada criança, explorando os espaços, materiais, atividades propostas, garantindo o bem-estar e o desenvolvimento para sua aprendizagem. A professora Rocha enfatiza que: “O processo precisa respeitar a identidade da criança, seu ritmo e bagagem. Deve acontecer de forma lúdica e prazerosa. Deve estar inserida em todo cotidiano escolar”. Enquanto a professora Água afirma: "Eu entendo que as crianças devam construir seus conhecimentos através da exploração de diferentes espaços, materiais, situações, mídias, pessoas, etc. com o professor como mediador, trabalhando de acordo com as necessidades e perfil de sua turma".

Segundo a lei n 9 9.394/1996 do artigo 3 (Seção II) da Lei de Diretrizes e Bases, “o ensino será ministrado com base nos seguintes princípios: liberdade de aprender, ensinar, pesquisar e divulgar a cultura, o pensamento, a arte e o saber" (BRASIL, 2018, p.9). Por isso é importante esta etapa que a educação infantil traz para o seu desenvolvimento e aprendizagem nesta primeira fase de sua iniciação escolar.

De acordo com as educadoras a avaliação dessa metodologia se dá de maneira prazerosa proporcionando bem-estar e interesse por buscar conhecimentos. A professora Semente destaca a importância em que: “as brincadeiras, a musicalização, os jogos, as pesquisas, as novas descobertas trazem maior aprendizagem para as crianças. Devemos valorizar sempre esses tipos de recursos para o melhor desenvolvimento da criança". Assim sendo, a aprendizagem torna-se de maneira espontânea e significativa levando as crianças a buscarem o novo para sua formação.

Saberes Pedagógicos, Criciúma, v. 4, n², maio/agosto 2020.- Curso de Pedagogia- UNESC 
Para avaliar a aplicação das metodologias as professoras realizam registros, pareceres descritivos, como destaca a professora Flor na avaliação de sua metodologia: "Através de relatório diário, observação e pareceres descritivos durante o semestre".

As professoras procuram inovar e estar atentas ao que acontece para trazer novas possibilidades e despertar o interesse e aprendizagem das crianças, bem como registros fotográficos, vídeos, analisando cada proposta realizada para responder os questionamentos do grupo. Tendo em vista os recursos metodológicos que cada educadora realiza, destacaremos a seguir a importância dos diferentes espaços naturais, para garantir, o processo de aprendizagem da criança na educação infantil.

\subsection{Os espaços de aprendizagem da educação infantil}

Observa-se que as professoras procuram estar inseridas nos diversos espaços que o ambiente escolar proporciona para que suas atividades sejam desenvolvidas de maneira diferenciada da proposta quando inserida dentro de uma sala de aula. De acordo com a resposta da professora Folha ao ser questionada sobre o uso de outros espaços, fica claro em sua resposta que: "Sim, utilizo todos os espaços que a escola dispõe como, parques, caixa de areia, sala de brinquedos, etc. Área coberta para trabalhos com pintura e colagens". Assim como a professora Terra destaca em sua resposta: "Sim. O ateliê de artes, pomar, biblioteca, auditório, sala de vídeo, campo, quadra, pátio, morro e pracinha sensorial”. Neste sentido, Horn (2017) afirma que é de fundamental importância realizar uma reflexão sobre os diferentes espaços naturais, e que os professores devem planejar suas atividades para além do espaço interno de sala de aula.

Para Horn (2017, p.33), os espaços vão além das salas de atividades como explicitado:

[...] Desde o hall de entrada, os corredores, a cozinha, o refeitório, os banheiros e as salas de atividades múltiplas até os pátios internos e externos, o princípio norteador de sua organização é convidar as crianças a estar neles, a acolhê-las, a permitir estar juntos uns com os outros. [...] Portanto, todos esses espaços e ambientes devem facilitar o crescimento infantil em todas as suas potencialidades, respondendo as necessidades da criança de se sentir completa em termos biológicos e culturais (HORN, 2017, p.33). 
É notória a importância que cada espaço, dentro do ambiente escolar, proporciona para o processo de ensino e aprendizagem de forma lúdica e prazerosa em cada atividade desenvolvida. Nesses espaços, as crianças se sentem livres para desenvolver as atividades. Pode-se observar como a agilidade, força, desenvoltura, noção de espaço, convívio com o grupo, flexibilidade nos movimentos, reflexo, se tornam perceptíveis e capaz para seu crescimento e aprendizagem.

As professoras percebem que existe uma maior interação entre as crianças que buscam explorar os ambientes com um olhar mais investigativo, questionador, instigando sua curiosidade, trazendo para si novas experiências e bem-estar em aprender de forma lúdica e prazerosa ao realizar as atividades. A professora Água, ao responder sobre esta interação que o espaço externo proporciona afirma que: “A aprendizagem em outros espaços possibilita diferentes tipos de exploração, deixando as crianças mais livres, tendo contato com a natureza, observando, questionando, buscando, etc. assim como, a professora Semente observa que: "As crianças sentem satisfação em realizar as atividades, costumam participar bem mais e sua memorização é bem melhor". Pode-se notar como é importante realizar as atividades nos espaços externos e como estes contribuem para a aprendizagem.

Buscando proporcionar um melhor acolhimento na realização das propostas, percebeu-se, na maioria das respostas, que as professoras procuram organizar os espaços para realizar suas atividades, dispondo de materiais para a efetivação da mesma. Sendo assim, a professora Terra afirma que: "Sim, ele é pensado e preparado de acordo com o objetivo da proposta, porém em outros momentos o espaço externo é disponibilizado para as crianças explorarem livremente buscando realizar seus próprios desafios sozinhos. Por exemplo, exploração no campo, pomar, morro,entre outros. Certos momentos preparamos desafios para as crianças, em outras situações vamos para o espaço para que ele mesmo explore livremente". A professora Água também destaca a importância em preparar o espaço: "Sim, em atividades planejadas nesses espaços sempre há um preparo, disposição de materiais e outras coisas necessárias, dependendo da atividade. Por exemplo, as crianças utilizam lupas para observar insetos no parque".

Existe uma intencionalidade para cada proposta assim sendo, buscam organizar-se de acordo com seus objetivos propostos. Horn (2017) destaca que:

Saberes Pedagógicos, Criciúma, v. 4, n², maio/agosto 2020.- Curso de Pedagogia- UNESC 
[...] Os espaços deverão possibilitar, portanto, a exploração por meio de todos os sentidos, a descoberta de características e relações dos objetos ou materiais mediante experiência direta, manipulação, transformação e combinação de materiais variados, a utilização do corpo com propriedade, a interação com outras crianças, enfim, a oportunidade de construir a própria autonomia na resolução de suas necessidades (HORN 2017, p.21).

Com isso, percebe-se a importância em ter um espaço preparado para atender as necessidades e experiências que ali serão desenvolvidas, tornando a aprendizagem mais significativa e rica em conhecimentos para as crianças e educadoras.

Através do olhar das educadoras é visível que as atividades realizadas no espaço externo indicam um momento de descontração, entusiasmo, interação entre os envolvidos. Para a professora Rocha: "São ambientes explorados com bastante entusiasmo, nesses ambientes além do que já é proposto pela educadora existe a beleza da natureza, do ar livre e as crianças são desafiadas a outras experiências, as que muitas vezes não são planejadas, mas estão implícitas nas situações”. A professora Folha também destaca sua importância quando propõe esse tipo de atividade: "Observo como elas aprendem e se divertem ao mesmo tempo, sentem satisfação ao realizar as atividades e aguardam ansiosas pelo dia de atividades fora da sala". A aprendizagem apresenta-se de forma espontânea e prazerosa, enriquecendo o objetivo proposto pelo educador. Arribas et al. (2004), citado por Horn (2017, p.88), destaca que:

[...] O espaço externo coloca a criança em situação de adaptar-se a novas experiências que exige dela novas respostas. A diversidade baseia-se nas possibilidades. Nesse ambiente, são propiciados vários e ricos intercâmbios, sendo amplamente contemplados o processo de socialização e de cooperação, oportunizando trocas com outros grupos de crianças, de diferentes faixas etárias [...]

Desta maneira observa-se que as educadoras possuem um olhar atento e enriquecedor ao proporcionar as atividades em ambientes que vão além das salas de aula, preocupando-se com o processo de ensino e aprendizagem no qual este espaço oferece.

A maneira que este espaço vai contribuir para a aprendizagem tem destaque no que as educadoras afirmam. A professora Rocha comenta que: “O espaço externo traz sempre a sensação de bem-estar as crianças. Quando estamos nos sentindo bem tudo ao nosso redor tem valor maior, por meio das emoções aprendemos de forma melhor, com as crianças isso não é diferente. Por isso esses espaços são tão importantes na educação infantil. A professora Semente

Saberes Pedagógicos, Criciúma, v. 4, n², maio/agosto 2020.- Curso de Pedagogia- UNESC 
destaca: "Contribui cada vez mais de maneira expressiva. O espaço externo é algo novo e são maneiras diferenciadas de aprender conteúdos que se forem planejados somente para a sala de aula se tornam cansativos para o desenvolvimento da criança”.

Observa-se como as educadoras acreditam na importância de "desemparedar" as crianças e a si mesmas, buscando no espaço externo momentos para desenvolver sua aprendizagem, tornando-as mais intensas e significativas. Para a professora Flor: "Muitas atividades que são realizadas nos espaços internos, podem e devem ser realizadas em outros espaços. Isso contribui para que a aprendizagem aconteça de uma maneira divertida e mais empolgante para as crianças. Ex.: ler um livro na sombra de uma árvore faz com que as crianças viagem ao mundo da fantasia e imaginação”.

É visível como cada conduta pode ter diferentes maneiras de serem realizadas, maneiras essas que buscam aprimorar seu desempenho e instigar sua imaginação, tornando seu ambiente propício a buscar novas experiências e explorações para seu desenvolvimento.

Ao fazer a análise de cada resposta contida no questionário apresentado a cada educadora, foi visível a importância que elas enfatizam para um bom planejamento, bem como, para realizar suas metodologias nas propostas planejadas. Percebe-se a importância que cada educadora busca para atividades que visam um melhor processo de ensino e aprendizagem, estando de acordo com a legislação e desenvolvendo o melhor para garantir o bem-estar que cada criança adquire nessa etapa da educação infantil.

Logo, com a realização destes questionamentos, ficou perceptível que o olhar das educadoras sobre as diferentes possibilidades de aprendizagens que os espaços naturais proporcionam as crianças na educação infantil, vão para além dos espaços internos de salas de aula. Assim sendo, percebe-se que as educadoras oportunizam as crianças desfrutar dos ambientes naturais, tornando a aprendizagem mais atrativa e significativa.

\section{CONCLUSÃO}

Este estudo buscou compreender a importância que o espaço externo proporciona para as crianças não só na educação infantil, mas em todos os momentos de convívio, seja no ambiente escolar, familiar ou social.

Saberes Pedagógicos, Criciúma, v. 4, n², maio/agosto 2020.- Curso de Pedagogia- UNESC 
Foi desenvolvido um estudo através de referências que conceituam a importância que o espaço externo proporciona para o processo de ensino e aprendizagem na educação infantil, bem como, aplicado um questionário onde nos trouxe a visão que as educadoras entrevistadas têm para este espaço e o quanto enfatizam sua relevância.

Percebeu-se nas respostas das educadoras entrevistadas, o quanto elas acreditam e possibilitam vivências em outros espaços, como o meio natural em convívio e contato direto com diferentes elementos naturais que o espaço escolar externo proporciona para a evolução da aprendizagem das crianças.

$\mathrm{Na}$ importância em desenvolver as atividades propostas no espaço externo, ficou evidenciada o quanto é fundamental brincar na natureza, pois traz uma série de benefícios para a aprendizagem e o convívio entre as crianças, tornando-as capaz, seguras, deparando-se com situações que as ajudarão a superar seus limites, criando possibilidades para explorar e conhecer o meio natural.

Em relação aos objetivos sobre a compreensão da educação infantil, percebe-se que as educadoras tem consciência na importância dessa etapa da educação básica para a aprendizagem na infância e quanto isso torna-se significativo para desenvolver as atividades propostas garantindo assim, seu melhor desempenho, bem como, a importância em ter um espaço preparado para receber as crianças, tornando este momento acolhedor para interagir e explorar todos os espaços internos e externos possíveis da escola.

Espero ter contribuído, com este estudo, para que novos olhares se voltem para o espaço externo e os educadores que não exploram, possam refletir sobre os benefícios que este ambiente proporciona para o bem-estar das crianças, assim como, para a evolução no processo de ensino e aprendizagem, bem como, para a interação e socialização com os demais do grupo.

Por fim, como sugestão para futuras pesquisas abordando a temática, espero que possa ser reflexivo sobre o ambiente externo e que os educadores possam atuar nesses espaços como pesquisadores influentes. 


\section{SABERES PEDAGÓGICOS}

Revista do Curso de Graduaçào de Pedagogia - Unesc

ISSN 2526.4559
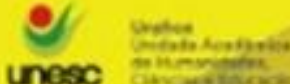

\section{REFERÊNCIAS:}

ALMEIDA, Rosângela Doin de; PASSINI, Elza Y. O espaço geográfico ensino e representação. São Paulo: Ed. Contexto, 1989.

BRASIL. Ministério da Educação. Diretrizes curriculares nacionais para a educação infantil /Secretaria de Educação Básica. - Brasília: MEC, SEB, DICEI, 2013. 562 p. Disponível em: <http://portal.mec.gov.br/docman/julho-2013-pdf/13677-diretrizes-educacaobasica-2013-pdf/file>. Acesso em ago. 2018.

BRASIL. Ministério da Educação. Lei de diretrizes e base da educação nacional. Lei n. 9394, de 20 de dezembro de 1996. Brasília: MEC, 2018. Disponível em:

<https://www2.senado.leg.br/bdsf/bitstream/handle/id/544283/lei_de_diretrizes_e_bases_2ed. pdf $>$. Acesso em set. 2018.

BRASIL. Ministério da Educação. Secretaria de Educação Básica. Base Nacional Comum Curricular. Brasília: MEC, 2018. Disponível em:<http://basenacionalcomum.mec.gov.br/images/BNCC_EI_EF_110518_versaofinal_site.p df >. Acesso em set. 2019.

DOURADO, Josiane Rodrigues. Breve histórico da Educação Infantil. São Paulo:

Pedagogia Ao Pé da Letra, 2012. Disponível em: <https://pedagogiaaopedaletra.com/brevehistorico-da-educacao-infantil/>. Acesso em: out. 2018.

FREIRE, Paulo. Pedagogia da Autonomia: Saberes necessários à prática educativa. São Paulo: Paz e Terra, 1996.

GIL, Antônio Carlos. Como elaborar projetos de pesquisa. 4. ed. - São Paulo: Atlas, 2002.

HORN, Maria da Graça Souza. Sabores, cores, sons, aromas. A organização dos espaços na educação infantil. Porto Alegre: Artmed, 2004.

HORN, Maria da Graça Souza. Brincar e interagir nos espaços da escola infantil. Porto Alegre: Penso, 2017.

KRAMER, Sônia et al (Org.). Infância e educação infantil. 6. ed. Campinas, SP: Papirus, 2007.

KRAMER, Sônia; LEITE, Maria Isabel (Org.). Infância: Fios e desafios da pesquisa. 9. ed. Campinas, SP: Papirus, 2007.

LIBÂNEO, José Carlos. Didática. 12. ed. São Paulo: Cortez, 1994. 


\section{SABERES PEDAGÓGICOS}

Revista do Curso de Graduaçào de Pedagogia - Unesc

ISSN 2526-4559

LIBÂNEO, José Carlos. Organização e Gestão da Escola: Teoria e Prática. 6. ed. São Paulo: Heccus, 2015.

PINHEIRO, José Maurício dos Santos. Da iniciação Científica ao TCC. Uma abordagem para os cursos de tecnologia. Rio Janeiro: Editora Ciência Moderna LTDA, 2010.

RINALDI, Carla. Diálogos com ReggioEmília: escutar, investigar,e aprender. São Paulo: Paz e Terra, 2012.

SANTOS, Milton. Metamorfose do espaço habitado: Fundamentos teóricos e metodológicos da Geografia. 6. ed. São Paulo: Editora da Universidade de São Paulo, 2008.

TIRIBA, Lea; BARROS, Maria Isabel Amando de (Org.). Desemparedamento da infância: A escola como lugar de encontro com a natureza. 2. ed. Rio de Janeiro: Alana, 2018.

VIGOTSKI, Lev Semenovich. A formação social da mente: o desenvolvimento dos processos psicológicos superiores. 6. ed. São Paulo: Martins Fontes, 1998. 